\title{
Comparison of Urea and Citric Acid Complexing Agents and Annealing Temperature Effect on the Structural Properties of $\gamma$ - and $\alpha$-Alumina Nanoparticles Synthesized by Sol-Gel Method
}

\author{
A. Rajaeiyan and M. M. Bagheri-Mohagheghi \\ School of Physics and Center for Solid State Physics Research, Damghan University, Damghan 91375-3889, Iran \\ Correspondence should be addressed to M. M. Bagheri-Mohagheghi; m_mohagheghee@yahoo.co.uk
}

Received 26 May 2013; Revised 24 August 2013; Accepted 6 September 2013

Academic Editor: Peter Majewski

Copyright (c) 2013 A. Rajaeiyan and M. M. Bagheri-Mohagheghi. This is an open access article distributed under the Creative Commons Attribution License, which permits unrestricted use, distribution, and reproduction in any medium, provided the original work is properly cited.

\begin{abstract}
A sol-gel method based on the Pechini process was used to synthesize different phases of alumina nanoparticles using a polymeric precursor with Aluminum nitrate. The emphasis was on investigating the effect of two different complexing agents, urea and citric acid, on the structural properties, particle size, and phase transformation during the heat treatment that was studied by XRD, TEM, SEM, BET, and FT-IR spectroscopy. The obtained results showed that particles do get fused together at high temperatures, and also the size of particles increases with the increase of annealing temperature. It was concluded that the size of $\alpha$-alumina synthesized by urea was $10-15 \mathrm{~nm}$, whereas the sample with citric acid yielded $\alpha$-powder with particle size of $200 \mathrm{~nm}$. Also, the resulting powder prepared by urea exhibited larger surface area $\left(84.2 \mathrm{~m}^{2} / \mathrm{gm}^{-1}\right)$ compared to citric acid $\left(39.92 \mathrm{~m}^{2} / \mathrm{gm}^{-1}\right)$ at $750^{\circ} \mathrm{C}$.
\end{abstract}

\section{Introduction}

Among various ceramics, alumina $\left(\mathrm{Al}_{2} \mathrm{O}_{3}\right)$ or sapphire, especially nanosized alumina, is one of the most important ceramic materials with exceptional properties such as high melting point, high temperature stability, high chemical inactivity, great hardness, and large band gap energy. Due to its excellent properties, it has many applications both as structural and functional materials such as heterogeneous catalyst or catalyst support, abrasive and adsorbent, cutting tool, and microelectronic and medical devices like surgical implants [1-4].

Alumina exists in a number of metastable transition phases as well as the thermodynamically stable $\alpha-\mathrm{Al}_{2} \mathrm{O}_{3}$ or corundum. These metastable alumina structures can be divided into two broad categories: a face-centered cubic arrangement of oxygen anions including $\gamma_{-}^{-}, \eta^{-}, \theta$-, and $\delta$-alumina, and a hexagonal close-packed arrangement of oxygen anions consisting of $\alpha-, \kappa-$, and X-alumina [5-7]. In the past decades, nanotechnology has become a key area in the development of science and engineering. Nanostructural materials have structural domains with diameters between
1 and $100 \mathrm{~nm}$. They are used potentially for many applications since the reduction of grain size to the nanometer scale can improve their physical and mechanical properties. Recently, much attention has been paid to the synthesis of nanocrystalline ceramics such as alumina ceramics. Among the physical and chemical methods devised for preparation of nanoscaled materials, synthesis from atomic or molecular precursors such as sol-gel route can give better control of particle size and homogeneity in particle distribution. It is a relatively simple processing technology that has been considered in the last three decades. Sol-gel enables materials to be mixed on a molecular level and bring out a solution, either as a colloidal gel, or as a polymerized macromolecular network $[8,9]$. Metal alkoxides are typical precursors, which undergo various forms of hydrolysis and polycondensation reactions. However, these metal alkoxide precursors have some disadvantages such as costs, flammability, moisture sensitivity, and toxicity. To overcome these problems, an alternative method for the production of fine powder is Pechini's method. Pechini processing involves the dissolution of metal salts in a mixture of a weak hydroxyl carboxylic acid as citric acid and a poly hydroxyl alcohol such as 
ethylene glycol. When the solution is heated at a certain temperature usually lower than $100^{\circ} \mathrm{C}$, a viscous organic precursor develops which can then be converted to the oxide by post-heating. Many preparation parameters like $\mathrm{pH}$, nature of salt and solute concentration, type of solvent, temperature, and drying conditions have to be judiciously controlled to obtain desired nanoparticles $[9,10]$.

A few number of papers discuss the effect of solgel process parameter on physical properties of $\alpha$-alumina nanoparticle. Kim et al. [11] studied aluminum nitrate precursor as compared to aluminum sulfate precursor. They conclude that the size of alumina nanoparticles obtained using aluminum nitrate precursor was smaller than that obtained using aluminum sulfate precursor, and the particles obtained from aluminum nitrate precursor have elongated shape, while those obtained from aluminum sulfate precursor have spherical shape. It was also observed that the temperature for complete transformation to $\alpha-\mathrm{Al}_{2} \mathrm{O}_{3}$ is lower in the case of using aluminum nitrate precursor as compared to aluminum sulfate precursor. Li et al. [12] investigated the molar ratio of citric acid to metal nitrate $(\mathrm{C} / \mathrm{N})$ in the sol-gel process which played an important role in phase transition and morphology controlling of alumina. Their results showed that the increasing molar ratio of $\mathrm{C} / \mathrm{N}$ was found to be in favor of $\gamma$ - to $\alpha-\mathrm{Al}_{2} \mathrm{O}_{3}$ phase transition, whereas the precursor with $\mathrm{C} / \mathrm{N}=1$ yielded a relatively well dispersed ultrafine $\gamma-\mathrm{Al}_{2} \mathrm{O}_{3}$ powder. Sharma et al. [13] demonstrated the critical role of $\mathrm{pH}$ in the sol-gel synthesis of alumina nanopowder. According to their results, by increasing the $\mathrm{pH}$ value from 2.5 to 12 , the particle size increases from 75 to $750 \mathrm{~nm}$. Also, the morphology of nanoparticle can be altered by changing $\mathrm{pH}$ of alumina sol. In another research [14], alumina nanopowder was synthesized by two different drying methods: (1) calcined at different temperatures and (2) by supercritical drying. They successfully obtained the hexagon sheet nano- $\gamma$-alumina particles with average size around 5-10 $\mathrm{nm}$ and more homogeneous dispersibility with the assistance of supercritical drying. While they had hard agglomerate nanoparticles in the first drying method that the phase transformation strongly depends on calcined temperature.

In the Pechini method, chelating occurs between complex cations and acid like citric acid, which is one of the leading basic chemical reactions as shown in Figure 1.

It seems that what makes difference in the performance of these material is the difference in the strength of bond formation with central atom of complex. So, various complexing agents behave differently, which should be considered. In this paper, we compared two different complexing agents (urea and citric acid) in the synthesis of alumina nanoparticle via sol-gel processing and Pechini's method. They are the most commonly used agents that is the reason why we have chosen them. These agents contain carboxylate or amine groups which are essential for the water-soluble complex precursor synthesis route. Citric acid contains carboxylate group, while urea contains aliphatic amine group. So they would behave differently in the methods of synthesis according to their ability in bond formation in complexes [15-18].

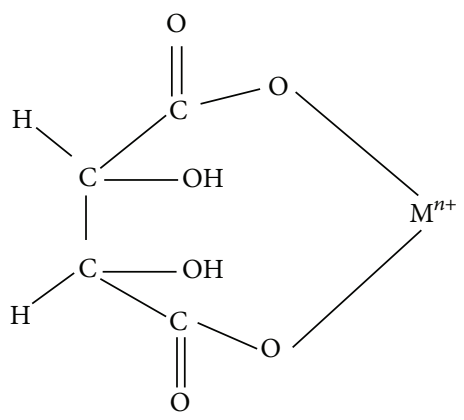

FIgURE 1: Chelating between complex cations and acid like citric acid.

\section{Experimental}

2.1. Synthesis. The starting solution was prepared by dissolving $0.1 \mathrm{M}$ aluminum nitrate nonahydrate $\left(\mathrm{Al}\left(\mathrm{NO}_{3}\right)_{3} \cdot 9 \mathrm{H}_{2} \mathrm{O}\right)$ in $100 \mathrm{~mL}$ deionized water and $100 \mathrm{~mL}$ ethanol to form a clear solution. The required amount of ethylene glycol and citric acid was added to the solution and heated at $40^{\circ} \mathrm{C}$ under vigorous magnetic stirring. The molar ratio of complexing agent and ethylene glycol to metal ions was $3: 1$ in the solution. Ethylene glycol functions as a spacer to modulate the distance between metal ions, preventing metal oxide particles from aggregation during earlier stages of organics removal. The aim of the polymeric organic net by esterification is to reduce any segregation of the cations. Then, the solution was continuously stirred for 4 hours and kept at a temperature of $80^{\circ} \mathrm{C}$ under reflux system until it turned to a yellowish sol. Then, the sol was heated in the oil bath at $100^{\circ} \mathrm{C}$ for 21 hours. With evaporation of the solvents, a transparent stick gel was gained. The beaker containing the aerogel was placed on a hot plate at $120^{\circ} \mathrm{C}$. It was concurrently heated from the top by infrared lamp radiation. During heating, the solution in the beaker was evaporated, and the gel started to swell and bubble. After 3 hours, a dried brownish xerogel was formed. The sol-gel precursors obtained were dried at $200^{\circ} \mathrm{C}$ in an oven and then grinded into a powder. Subsequently, the powder was put into the porcelain crucible and calcined in a muffle furnace at different temperatures $(750,1000$, and $1250^{\circ} \mathrm{C}$ ) for 1 hour. In the next step, with maintaining all experiment conditions, we used urea as complexing agent instead of citric acid. To get an accurate comparison, the molar ratio of materials used in the second experiment was same as the first experiment; that is, we used $0.1 \mathrm{~mol}$ Aluminum nitrate nonahydrate $\left(\mathrm{Al}\left(\mathrm{NO}_{3}\right)_{3} \cdot 9 \mathrm{H}_{2} \mathrm{O}\right)$ dissolved in $100 \mathrm{~mL}$ deionized water and $100 \mathrm{~mL}$ ethanol. Like the previous experiment, the molar ratio of urea as complexing agent and ethylene glycol to metal ions was three to one in the solution. In this condition, at the heating step of the aerogel, the sample suddenly foamed up and caught fire, leaving a finely black-colored powder.

2.2. Characterization. To identify phases and their crystallinity, powder X-ray diffraction (XRD) studies were carried out by D 8 Advance Bruker diffractometer using $\operatorname{CuK} \alpha(\lambda=$ $0.15406 \mathrm{~nm}$ ), radiation in the $2 \theta$ range from $20^{\circ}$ to $70^{\circ}$. The 
TABLE 1: Weight loss of powders versus annealing temperatures.

\begin{tabular}{lcc}
\hline Complexing agent & $\begin{array}{c}\text { Weight loss } \\
T=750^{\circ} \mathrm{C}\end{array}$ & $\begin{array}{c}\text { Weight loss } \\
T=1000^{\circ} \mathrm{C}\end{array}$ \\
\hline Urea & $86 \%$ & $89 \%$ \\
Citric acid & $90 \%$ & $92 \%$ \\
\hline
\end{tabular}

average crystallite size $(D)$ was calculated using Scherrer's formula [19],

$$
D=\frac{K \lambda}{\beta \cos \theta},
$$

where $\beta$ is the full width at half maximum (FWHM) of the corresponding XRD peak at radiant. $K=0.9$ is correction factor, $\lambda$ is $X$-ray wavelength $(\lambda=0.15406 \mathrm{~nm})$, and $\theta$ is the Bragg diffraction angle. Scanning electron microscopy (Leo $430 \mathrm{I}$ ) and transmission electron microscopy (LEO (912 AB)) were used to observe and analyze the morphology and the particle size of the powders. The different absorption bands corresponding to the gel and additives were determined by Fourier transform infrared spectra analysis (FT-IR) using $\mathrm{KBr}$ disk technique with a Perkin Elmer-RXI with $k=$ $4000-400 \mathrm{~cm}^{-1}$. The specific surface areas were calculated by the Brunauer-Emmett-Teller (BET) equation using the data in the $P / P_{0}$ range of $0.09-0.3$ and outgas temperature of $200^{\circ} \mathrm{C}$. The specific surface area (SSA) was converted into particle size assuming that the particles are closed spheres with smooth surface and uniform size using

$$
D_{\mathrm{BET}}=\frac{6 \times 10^{3}}{d_{\mathrm{th}} S_{\mathrm{BET}}},
$$

where $d_{\text {th }}$ is the theoretical density of the material under consideration, $D_{\mathrm{BET}}$ is the average particle size in $\mathrm{nm}$, and $S_{\mathrm{BET}}$ is the specific surface area expressed in $\mathrm{m}^{2} \mathrm{gm}^{-1}$ [16].

\section{Results and Discussion}

3.1. Structural Properties. Figures 2(a)-2(c) show comparative XRD patterns of the as-synthesized powder obtained with citric acid and urea calcined at different temperatures. It was found that the phase transformation strongly depends on calcined temperature. As shown by the XRD pattern at $750^{\circ} \mathrm{C}$, there are broad peaks which are indications of crystallite structure formation and nanosized dimension [20]. At this temperature for the sample obtained from urea, Figure 2(a)(B) indicates the formation of poorly crystallized alumina, as broad peaks indexed for $\gamma-\mathrm{Al}_{2} \mathrm{O}_{3}$. Indeed, at this temperature, aqueous amorphous $\mathrm{Al}_{2} \mathrm{O}_{3}$ phase exists which is also seen in [21], which is introduced as a precursor of gamma alumina. But for the sample obtained from citric acid, diffraction peaks attributed to $\gamma$-alumina appeared. The broadness of peaks implies a low crystallization [14]. The black color of powder at this temperature shows the existence of organic materials, also confirmed XRD pattern so that these compounds have prevented the formation of crystal structure.

With the increase of calcination temperature up to $1000^{\circ} \mathrm{C}$, crystallinity of $\gamma-\mathrm{Al}_{2} \mathrm{O}_{3}$ improved. The $\gamma-\mathrm{Al}_{2} \mathrm{O}_{3}$ crystallized in a defective spinel lattice with aluminum located in tetragonal position. Such a lattice is unstable and should transform into stable form at high temperatures. At $1000^{\circ} \mathrm{C}$, weak peaks of $\delta-\mathrm{Al}_{2} \mathrm{O}_{3}$ were observed, which is an essential intermediate phase for the transformation of gamma to alpha at higher temperatures [22]. At this temperature in the case of using urea, characteristic peaks of $\alpha-\mathrm{Al}_{2} \mathrm{O}_{3}$ appear with a rather weak intensity, which indicate the starting point of $\gamma$ - to $\alpha-\mathrm{Al}_{2} \mathrm{O}_{3}$ transition.

It can be seen that the phase transformation temperature to alpha phase is lower in the case of urea precursor compared to citric acid precursor. It was reported that $\mathrm{NH}_{4} \mathrm{NO}_{3}$ is formed during the preparation of alumina from aluminum nitrate and urea according to the following chemical reactions [23]:

$$
\begin{aligned}
& 2 \mathrm{Al}\left(\mathrm{NO}_{3}\right)_{3}+3 \mathrm{NH}_{2}-\mathrm{CO}-\mathrm{NH}_{2}+(x+6) \mathrm{H}_{2} \mathrm{O} \\
& \quad \longrightarrow \mathrm{Al}_{2} \mathrm{O}_{3} \cdot x \mathrm{H}_{2} \mathrm{O}+6 \mathrm{NH}_{4} \mathrm{NO}_{3}+3 \mathrm{CO}_{2} \\
& 2 \mathrm{Al}\left(\mathrm{NO}_{3}\right)_{3}+4 \mathrm{NH}_{2}-\mathrm{CO}-\mathrm{NH}_{2}+(x+7) \mathrm{H}_{2} \mathrm{O} \\
& \quad \longrightarrow \mathrm{Al}_{2} \mathrm{O}_{3} \cdot x \mathrm{H}_{2} \mathrm{O}+6 \mathrm{NH}_{4} \mathrm{NO}_{3}+2 \mathrm{NH}_{3}+4 \mathrm{CO}_{2} \\
& \quad 2 \mathrm{Al}\left(\mathrm{NO}_{3}\right)_{3}+7 \mathrm{NH}_{2}-\mathrm{CO}-\mathrm{NH}_{2}+(x+14) \mathrm{H}_{2} \mathrm{O} \\
& \quad \longrightarrow \mathrm{Al}_{2} \mathrm{O}_{3} \cdot x \mathrm{H}_{2} \mathrm{O}+6 \mathrm{NH}_{4} \mathrm{NO}_{3}+4\left(\mathrm{NH}_{4}\right)_{4} \mathrm{CO}_{3}+3 \mathrm{CO}_{2}
\end{aligned}
$$

After that, $\mathrm{NH}_{4} \mathrm{NO}_{3}$ decomposes and releases a large amount of energy during calcination, leading to the decrease of temperature for the complete transformation of $\gamma$ - to $\alpha$ alumina [24]. Single-phase $\alpha-\mathrm{Al}_{2} \mathrm{O}_{3}$ was completely formed after calcinations at $1250^{\circ} \mathrm{C}$ for both samples. The diffraction pattern was extremely sharp indicating the existence of a highly crystalline material. Since all the organic materials were burnt off during calcination at elevated temperatures, the powder was completely white. Table 1 shows weight loss of powders after calcination temperatures.

3.2. Particle Size and Specific Surface Area. The XRD parameters and the calculated crystallite sizes using Scherrer's formula are presented in Table 2. Irrespective of the preparation conditions, all the samples exhibited a crystallite size of around $6.5-8.5 \mathrm{~nm}$ at $1000^{\circ} \mathrm{C}$ and $28-38 \mathrm{~nm}$ at $1250^{\circ} \mathrm{C}$. Table 3 shows the BET surface area of powders and the particle size calculated from (2) using alumina density of $3.98 \mathrm{~g} / \mathrm{cm}^{3}$. A large particle size calculated from surface area compared to the crystallite size measured by XRD illustrates the rate of agglomeration of the particles. The surface area was higher for the urea complexing agent (84.2) compared to citric acid (39.92) which is in agreement with the size of nanoparticle, as the particle size becomes small, the specific surface area is increased. From Table 3, it is indicated that upon annealing, due to the increased grain growth during the phase transformation from $\gamma-\mathrm{Al}_{2} \mathrm{O}_{3}$ to $\alpha-\mathrm{Al}_{2} \mathrm{O}_{3}$, a substantial reduction in surface area had occurred.

3.3. SEM and TEM Observations. The effect of complexing agents on the structure of nanoparticles can be clearly seen 


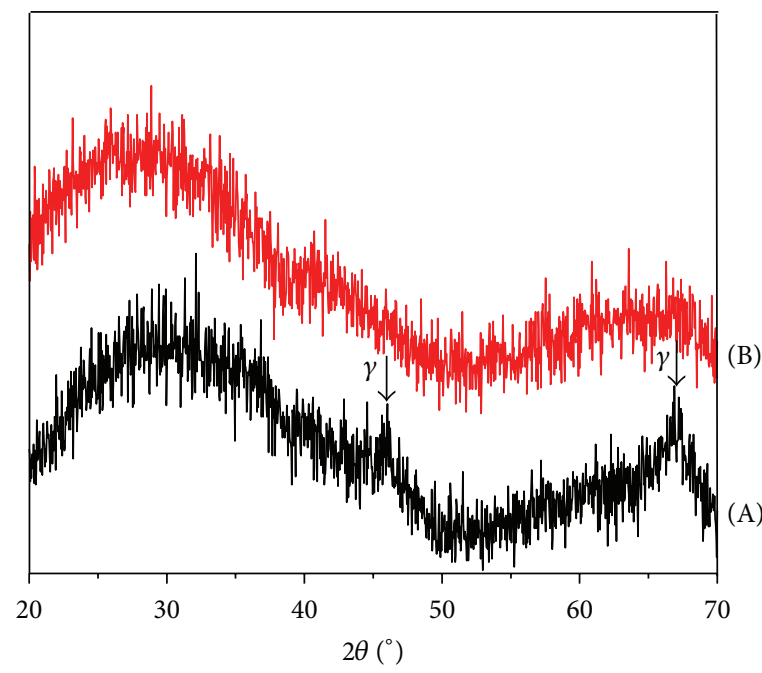

(a) $750^{\circ} \mathrm{C}$

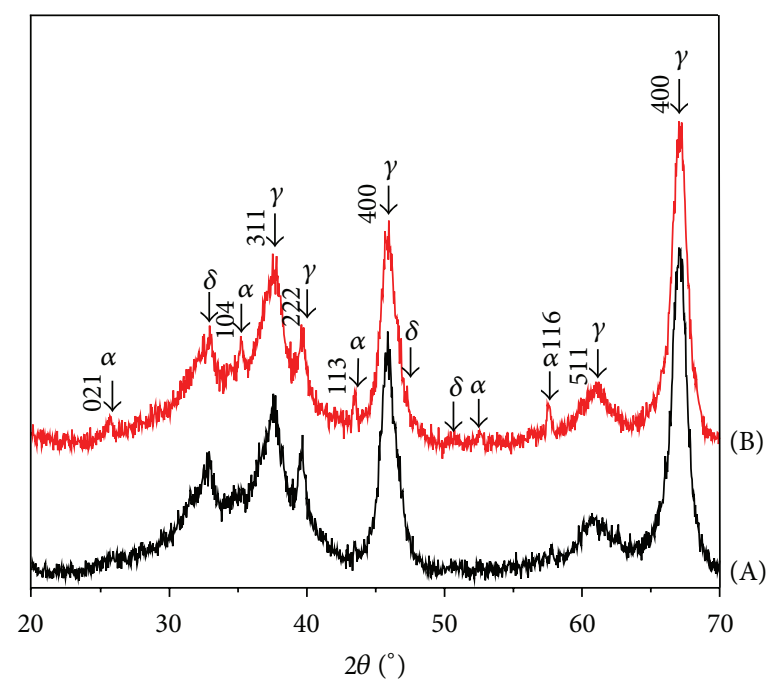

(b) $1000^{\circ} \mathrm{C}$

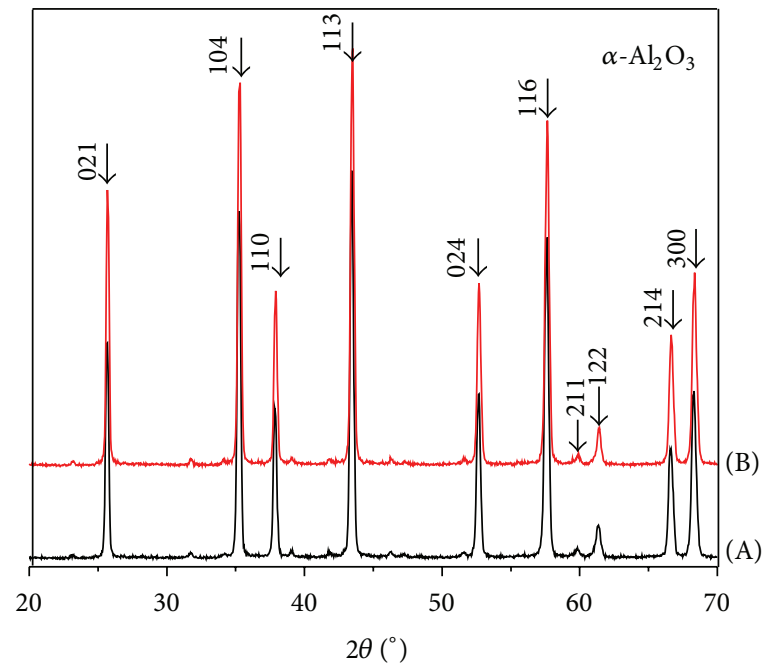

(c) $1250^{\circ} \mathrm{C}$

FIGURE 2: XRD patterns of $\mathrm{Al}_{2} \mathrm{O}_{3}$ nanopowder prepared with complexing agent. (A) Citric acid and (B) urea calcined at temperatures of (a) $750^{\circ} \mathrm{C}$, (b) $1000^{\circ} \mathrm{C}$, and (c) $1250^{\circ} \mathrm{C}$.

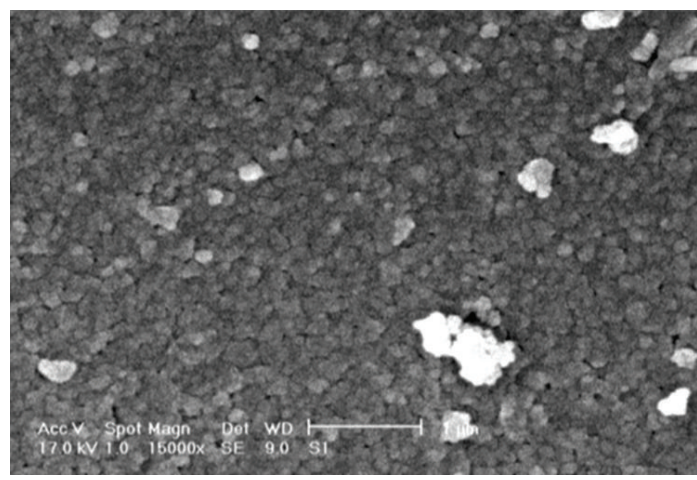

(a) $750^{\circ} \mathrm{C}$

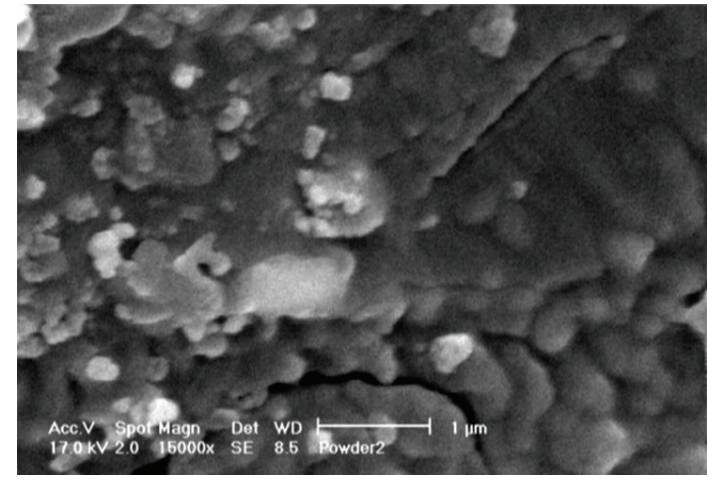

(b) $1250^{\circ} \mathrm{C}$

Figure 3: SEM images of $\mathrm{Al}_{2} \mathrm{O}_{3}$ nanoparticles prepared by urea calcined at (a) $750^{\circ} \mathrm{C}$ and (b) $1250^{\circ} \mathrm{C}$. 
TABLE 2: Summary of XRD measurements for $\mathrm{Al}_{2} \mathrm{O}_{3}$ samples.

\begin{tabular}{|c|c|c|c|c|c|c|c|}
\hline Complexing agent & $h k l$ & $2 \theta(\mathrm{deg})$ & $\begin{array}{c}\text { Intensity } \\
\text { (cps) }\end{array}$ & $\begin{array}{c}d(\AA) \\
\text { Lattice distance }\end{array}$ & $\begin{array}{c}\text { FWHM } \\
\text { (deg) }\end{array}$ & $\begin{array}{c}D(\mathrm{~nm}) \\
\text { Crystalite size }\end{array}$ & $\begin{array}{c}\text { Identification with } \\
(h k l) \text { value }\end{array}$ \\
\hline \multirow{9}{*}{ Citric acid } & \multicolumn{7}{|c|}{$T=1000^{\circ} \mathrm{C}$} \\
\hline & 440 & 67.08 & 712 & 1.39 & 1.14 & 8.60 & $\gamma-\mathrm{Al}_{2} \mathrm{O}_{3} ;$ Cubic \\
\hline & 400 & 45.86 & 528 & 1.97 & 1.19 & 7.50 & $\gamma-\mathrm{Al}_{2} \mathrm{O}_{3} ;$ Cubic \\
\hline & 311 & 37.56 & 426 & 2.39 & 1.17 & 7.40 & $\gamma-\mathrm{Al}_{2} \mathrm{O}_{3} ;$ Cubic \\
\hline & \multicolumn{7}{|c|}{$T=1250^{\circ} \mathrm{C}$} \\
\hline & 113 & 43.44 & 3346 & 2.08 & 0.29 & 30.50 & $\alpha-\mathrm{Al}_{2} \mathrm{O}_{3} ;$ Hexagonal \\
\hline & 104 & 35.23 & 3031 & 2.54 & 0.28 & 31.00 & $\alpha-\mathrm{Al}_{2} \mathrm{O}_{3} ;$ Hexagonal \\
\hline & 116 & 57.59 & 2774 & 1.59 & 0.32 & 28.87 & $\alpha-\mathrm{Al}_{2} \mathrm{O}_{3} ;$ Hexagonal \\
\hline & 012 & 25.62 & 1885 & 3.46 & 0.27 & 30.53 & $\alpha-\mathrm{Al}_{2} \mathrm{O}_{3} ;$ Hexagonal \\
\hline \multicolumn{8}{|c|}{$T=1000^{\circ} \mathrm{C}$} \\
\hline \multirow{10}{*}{ Urea } & 440 & 67.11 & 705 & 1.39 & 1.153 & 8.60 & $\gamma-\mathrm{Al}_{2} \mathrm{O}_{3} ;$ Cubic \\
\hline & 400 & 45.96 & 499 & 1.97 & 0.999 & 8.90 & $\gamma-\mathrm{Al}_{2} \mathrm{O}_{3} ;$ Cubic \\
\hline & 311 & 37.52 & 446 & 2.39 & 1.3 & 6.70 & $\gamma-\mathrm{Al}_{2} \mathrm{O}_{3} ;$ Cubic \\
\hline & 104 & 35.23 & 289 & 2.54 & 0.227 & 38.24 & $\alpha-\mathrm{Al}_{2} \mathrm{O}_{3} ;$ Hexagonal \\
\hline & 113 & 43.519 & 180 & 2.07 & 0.303 & 29.40 & $\alpha-\mathrm{Al}_{2} \mathrm{O}_{3} ;$ Hexagonal \\
\hline & \multicolumn{6}{|c|}{$T=1250^{\circ} \mathrm{C}$} & $\alpha-\mathrm{Al}_{2} \mathrm{O}_{3} ;$ Hexagonal \\
\hline & 113 & 43.48 & 3608 & 2.07 & 0.29 & 30.72 & $\alpha-\mathrm{Al}_{2} \mathrm{O}_{3} ;$ Hexagonal \\
\hline & 104 & 35.28 & 3334 & 2.54 & 0.27 & 31.23 & $\alpha-\mathrm{Al}_{2} \mathrm{O}_{3} ;$ Hexagonal \\
\hline & 116 & 57.63 & 2980 & 1.59 & 0.32 & 29.14 & $\alpha-\mathrm{Al}_{2} \mathrm{O}_{3} ;$ Hexagonal \\
\hline & 012 & 25.0 & 2386 & 3.46 & 0.26 & 32.00 & $\alpha-\mathrm{Al}_{2} \mathrm{O}_{3} ;$ Hexagonal \\
\hline
\end{tabular}

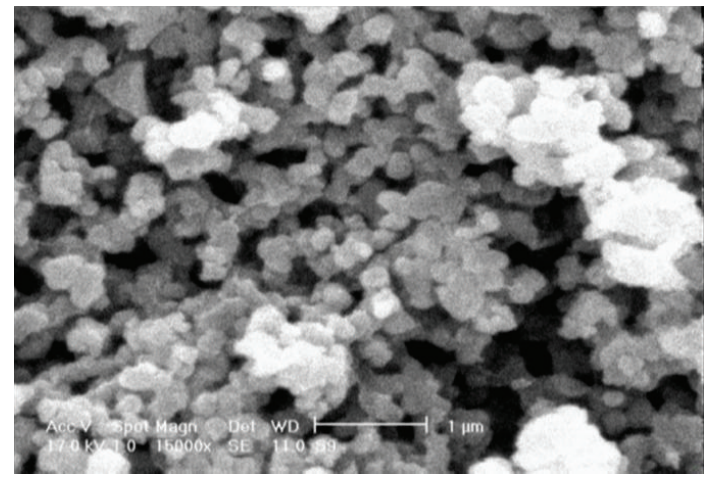

(a) $750^{\circ} \mathrm{C}$

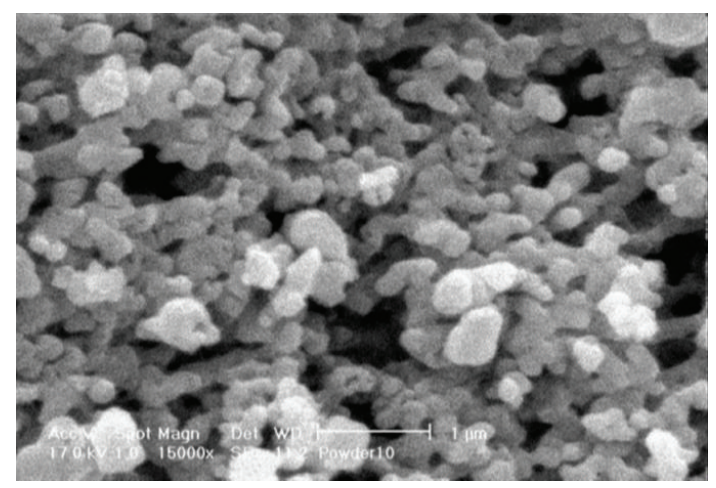

(b) $1250^{\circ} \mathrm{C}$

FIgURE 4: SEM image of $\mathrm{Al}_{2} \mathrm{O}_{3}$ nanoparticles prepared by citric acid calcined at (a) $750^{\circ} \mathrm{C}$ and (b) $1250^{\circ} \mathrm{C}$.

from the SEM and TEM images. Figures 3 and 4 present SEM image of nanoparticles calcined at $750^{\circ} \mathrm{C}$ and $1250^{\circ} \mathrm{C}$ prepared by urea and citric acid, respectively. Figure 5 shows a comparison in TEM images between the particle as produced from urea and citric acid at $1250^{\circ} \mathrm{C}$. Electronic Microscopic images reveal that hard agglomeration occurred at high temperatures, and the size distribution of nanoparticle is mostly uniform. Due to the agglomeration, the determination of the average diameter was hard because individual particle boundaries were not clearly distinguishable. But with more accuracy the size of particles before hard agglomeration is possible to estimate. From TEM images, the size of particles produced with citric acid is about $200 \mathrm{~nm}$, and those prepared from urea are about $10-15 \mathrm{~nm}$. Probably due to using the urea and spontaneous combustion process, the particles did not have any chance for growth and had smaller size. In order to study the effect of calcinations temperature on the size of particles, TEM image of nanoalumina obtained from urea calcined at $750^{\circ} \mathrm{C}$ is also shown in Figure 6. At this temperature, due to presence of organic compounds in powder, there is an opaque background so that the particles are not properly observed and are consistent with black color of powder and XRD diagrams at $750^{\circ} \mathrm{C}$. With a smaller-scale image, extremely fine particles with a size of about $6-8 \mathrm{~nm}$ 


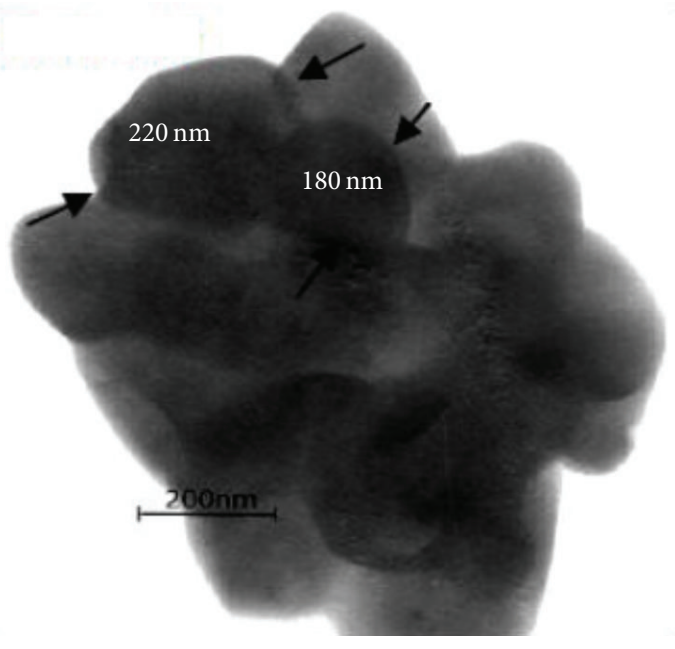

(a) Citric acid

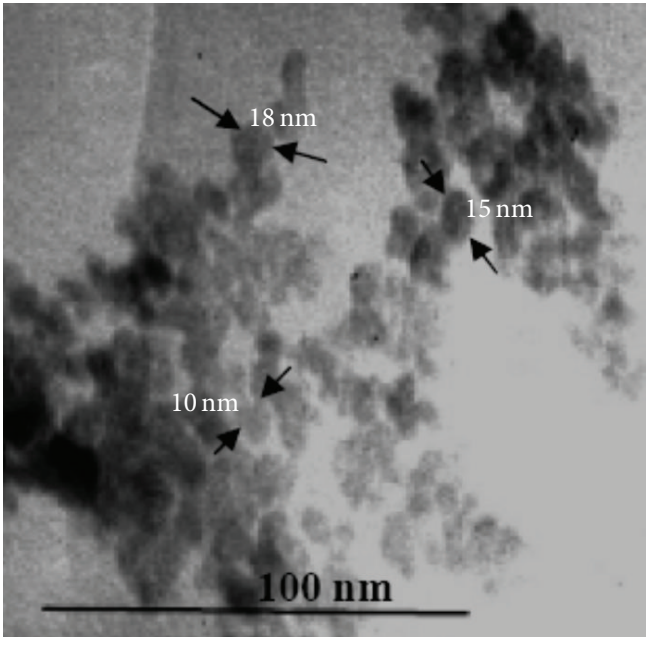

(b) Urea

FIgURE 5: TEM images of $\mathrm{Al}_{2} \mathrm{O}_{3}$ nanoparticles prepared with complexing agent. (a) Citric acid and (b) urea calcined at $1250^{\circ} \mathrm{C}$ for 1 hour.

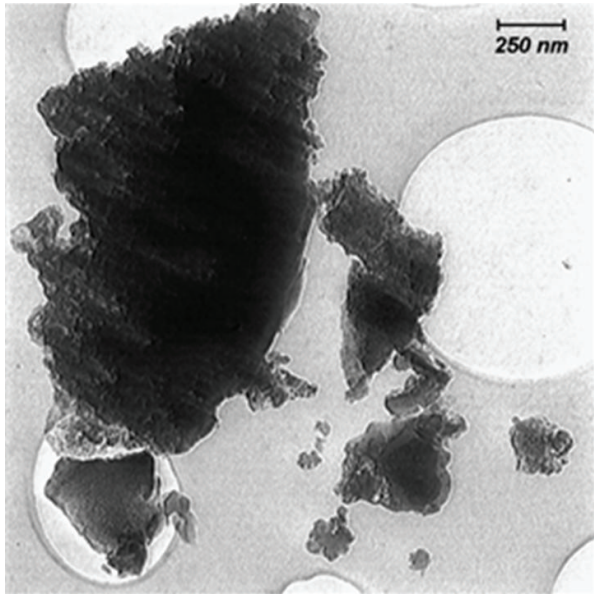

(a) Urea $\left(750^{\circ} \mathrm{C}\right)$

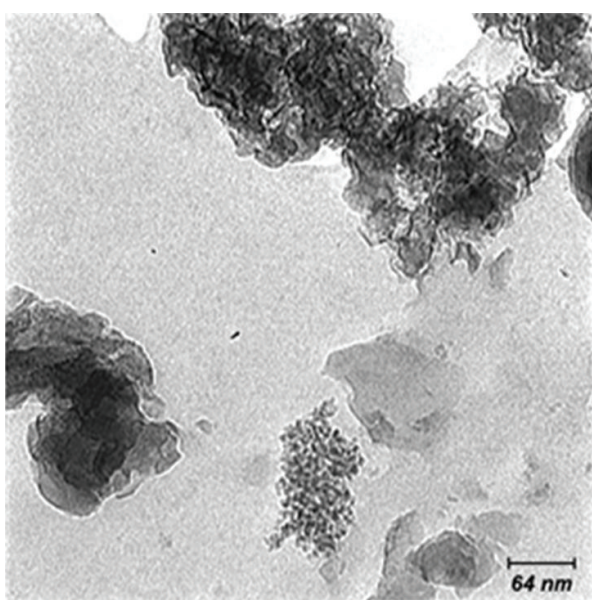

(c) Urea $\left(750^{\circ} \mathrm{C}\right)$

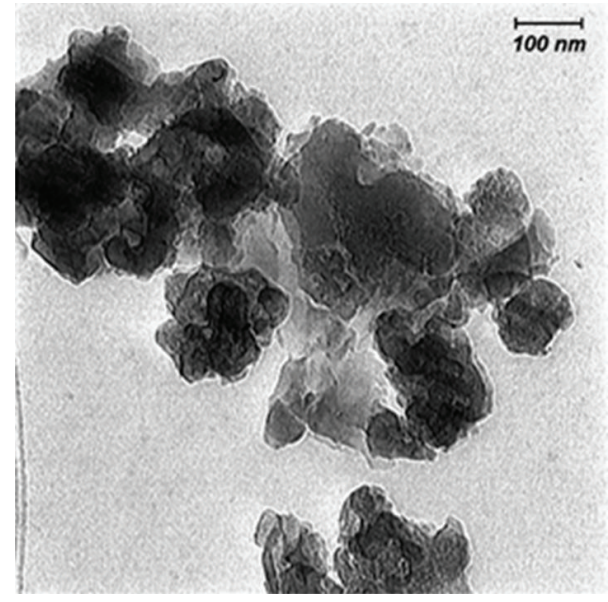

(b) Urea $\left(750^{\circ} \mathrm{C}\right)$

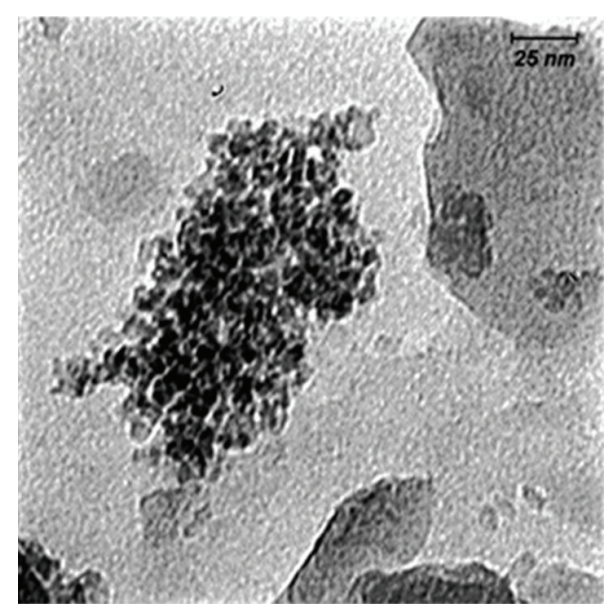

(d) Urea $\left(750^{\circ} \mathrm{C}\right)$

FIGURE 6: TEM images of $\mathrm{Al}_{2} \mathrm{O}_{3}$ nanoparticles prepared with urea at $750^{\circ} \mathrm{C}$ at different scales of the microscope image. 


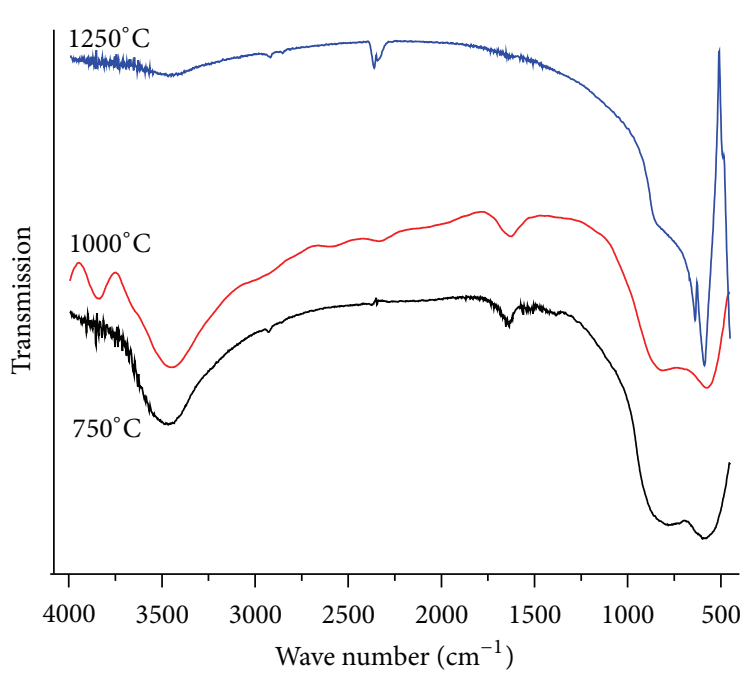

(a) Citric acid

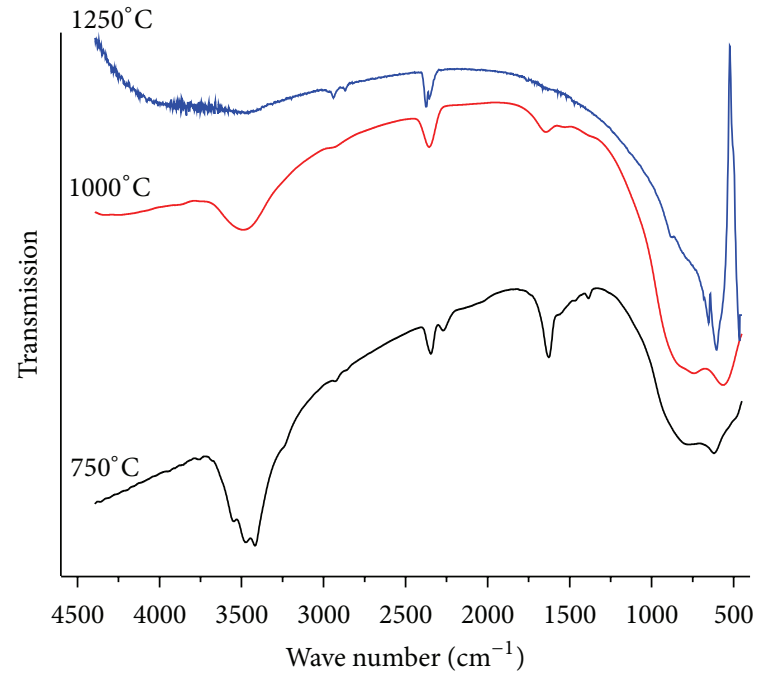

(b) Urea

FIGURE 7: FT-IR spectrums of $\mathrm{Al}_{2} \mathrm{O}_{3}$ nanopowders prepared with complexing agent. (a) Citric Acid and (b) urea calcined at various temperatures.

TABLE 3: BET surface area of powders and the particle size versus annealing temperatures.

\begin{tabular}{lcccc}
\hline Complexing agent & $S_{\mathrm{BET}}\left(\mathrm{m}^{2} / \mathrm{g}\right)$ & $D_{\mathrm{BET}}(\mathrm{nm})$ & $S_{\mathrm{BET}}\left(\mathrm{m}^{2} / \mathrm{g}\right)$ & $D_{\mathrm{BET}}(\mathrm{nm})$ \\
$T=750^{\circ} \mathrm{C}$ & $T=750^{\circ} \mathrm{C}$ & $1250^{\circ} \mathrm{C}$ & 87 \\
\hline Urea & 84.2 & 18 & 17.4 & $-1250^{\circ} \mathrm{C}$ \\
Citric acid & 39.92 & 38 & - & - \\
\hline
\end{tabular}

can be seen which become larger with increasing temperature as shown in Figure 6(b).

From SEM images, it can be observed that the particles have elongated shape. It seems that the open structure of the gelatinous precipitate formed from precursor allowed alumina crystallites agglomeration freely, resulting in the evolution of the typical morphology, namely, elongated structure $[24,25]$.

3.4. FT-IR Spectra. Plots (a) and (b) in Figure 7 illustrate the infrared spectrum of the powders annealed at 750,1000, and $1250^{\circ} \mathrm{C}$ for each complexing agent that shows similar features. At $750^{\circ} \mathrm{C}$, a broad band around $3500 \mathrm{~cm}^{-1}$ and an absorption one at $1635 \mathrm{~cm}^{-1}$ are observed, which are assigned to bending and stretching vibration of hydroxylate group $(\mathrm{O}-\mathrm{H})$ in the adsorbed water, respectively [26]. It can be seen that the infrared spectra tend to possess a double-peak at $\sim 800 \mathrm{~cm}^{-1}$ and $\sim 600 \mathrm{~cm}^{-1}$ that are assigned to aluminium ions in octahedral and tetrahedral environment and indicating the presence of $\gamma$-phase at this temperature [27, 28]. The low intensity of these peaks indicates that it is at the beginning of gamma phase formation. With increasing temperature up to $1000^{\circ} \mathrm{C}$, these broad bands divided into two clear distinct peaks represent that the $\gamma$-phase formation is complete at this temperature $[27,28]$. This is in agreement with the presence of $\gamma$-alumina diffraction peaks observed in the XRD pattern at $750^{\circ} \mathrm{C}$ and $1000^{\circ} \mathrm{C}$. At $1250^{\circ} \mathrm{C}$, sharp absorption peaks at 450,600 , and $650 \mathrm{~cm}^{-1}$ and the other with less intensity at
$780 \mathrm{~cm}^{-1}$ appear which are identified to be the characteristics absorption bands of $\alpha-\mathrm{Al}_{2} \mathrm{O}_{3}$ with a corundum structure that is built up only on octahedral $\mathrm{AlO}_{6}$ [12]. The high intensity of these peaks is proportional to the XRD pattern at $1250^{\circ} \mathrm{C}$. Absorption at $\sim 2350 \mathrm{~cm}^{-1}$ that increases with temperature is stretching the vibration of $\mathrm{HCO}_{3}{ }^{-}$group, related to the atmospheric $\mathrm{H}_{2} \mathrm{O}$ and $\mathrm{CO}_{2}$ adsorbed on the metallic cations [29]. In the pattern Figure $6(\mathrm{a})$ at $750^{\circ} \mathrm{C}$, the peak centered at $\sim 1390 \mathrm{~cm}^{-1}$ indicates that $\mathrm{NO}_{3}{ }^{-}$disappears by increasing temperature [27], and the one at $2341 \mathrm{~cm}^{-1}$ is related to $\mathrm{CO}_{2}$ absorption from the surrounding environment by metal cations that did not remove even with increasing temperature [28].

\section{Conclusion}

Different phases of alumina nanoparticles with elongated and uniform structure were synthesized by sol-gel method using aluminum nitrate and two different complexing agents: urea and citric acid. The following was found.

(a) According to XRD patterns, using the citric acid lowers the formation temperature of $\gamma-\mathrm{Al}_{2} \mathrm{O}_{3}$. So concerning citric acid, this phase is formed at $T=$ $750^{\circ} \mathrm{C}$ while regarding urea, it formed at $T=1000^{\circ} \mathrm{C}$, this is confirmed by IR spectra.

(b) Urea has reduced the phase transition temperature to Alpha- $\mathrm{Al}_{2} \mathrm{O}_{3}$ so that at $1000^{\circ} \mathrm{C}$ low intensity $\delta$ - and 
$\alpha$-peaks are observed in the case of using urea, and it may be due to the formation of $\mathrm{NH}_{4} \mathrm{NO}_{3}$, which is decomposed with releasing large amounts of energy during annealing. But for citric acid just peaks of $\gamma$ is observed. So we introduce urea as a fuel of reaction at high temperatures.

(c) With increasing temperature up to $1250^{\circ} \mathrm{C}$, high intensity and sharp peaks of $\alpha$-alumina are observed for both samples that shows very high crystallization at this temperature and is consistent with FT-IR spectra at $1250^{\circ} \mathrm{C}$.

(d) According to electron microscope images, the size of alumina nanoparticles obtained using urea (10$15 \mathrm{~nm}$ ) was so smaller and more uniform than those obtained using citric acid $(200 \mathrm{~nm})$, and their BET surface areas are 84.2 and $39.92 \mathrm{~m}^{2} / \mathrm{g}$, respectively.

(e) Due to lower molecular weight of urea compared to citric acid, the remaining powder prepared by urea was more than the powder prepared by citric acid, so we suggest urea instead of citric acid in commercial and industrial applications.

\section{References}

[1] G. A. Zacheis, K. A. Gray, and P. V. Kamat, "Radiation-induced catalysis on oxide surfaces: degradation of hexachlorobenzene on $\gamma$-irradiated alumina nanoparticles," Journal of Physical Chemistry B, vol. 103, no. 12, pp. 2142-2150, 1999.

[2] S. K. Dhoke, T. J. Mangal Sinha, and A. S. Khanna, "Effect of nano- $\mathrm{Al}_{2} \mathrm{O}_{3}$ particles on the corrosion behavior of alkyd based waterborne coatings," Journal of Coatings Technology Research, vol. 6 , no. 3, pp. 353-368, 2009.

[3] E. U. Ezugwu, J. Bonney, and R. B. da Silva, "Evaluation of the performance of different nano-ceramic tool grades when machining nickel-base, inconel 718, alloy," The Journal of the Brazilian Society of Mechanical Sciences and Engineering, vol. 26, no. 1, pp. 12-16, 2004.

[4] S. Pacheco and R. Rodríguez, "Adsorption properties of metal ions using alumina nano-particles in aqueous and alcoholic solutions," Journal of Sol-Gel Science and Technology, vol. 20, no. 3, pp. 263-273, 2001.

[5] P. Souza Santos, H. Souza Santos, and S. P. Toledo, "Standard transition aluminas. Electron microscopy studies," Materials Research, vol. 3, no. 4, pp. 104-114, 2000.

[6] B. Kasprzyk-Hordern, "Chemistry of alumina, reactions in aqueous solution and its application in water treatment," Advances in Colloid and Interface Science, vol. 110, no. 1-2, pp. 19-48, 2004.

[7] I. Levin and D. Brandon, "Metastable alumina polymorphs: crystal structures and transition sequences," Journal of the American Ceramic Society, vol. 81, no. 8, pp. 1995-2012, 1998.

[8] A. J. Perrotta, "Nanosized corundum synthesis," Material Research Innovations, vol. 2, no. 1, pp. 33-38, 1998.

[9] L. Le Bihan, F. Dumeignil, E. Payen, and J. Grimblot, "Chemistry of preparation of alumina aerogels in presence of a complexing agent," Journal of Sol-Gel Science and Technology, vol. 24, no. 2, pp. 113-120, 2002.

[10] Z. Wang, Y. Liu, and Z. Zhang, Handbook of Nanophase and Nanostructured Material, Kluwer Academic, 2002.
[11] H. J. Kim, T. G. Kim, J. J. Kim, S. S. Park, S. S. Hong, and G. D. Lee, "Influences of precursor and additive on the morphology of nanocrystalline $\alpha$-alumina," Journal of Physics and Chemistry of Solids, vol. 69, no. 5-6, pp. 1521-1524, 2008.

[12] J. Li, Y. Pan, C. Xiang, Q. Ge, and J. Guo, "Low temperature synthesis of ultrafine $\alpha-\mathrm{Al}_{2} \mathrm{O}_{3}$ powder by a simple aqueous solgel process," Ceramics International, vol. 32, no. 5, pp. 587-591, 2006.

[13] P. K. Sharma, V. V. Varadan, and V. K. Varadan, "A critical role of $\mathrm{pH}$ in the colloidal synthesis and phase transformation of nano size $\alpha-\mathrm{Al}_{2} \mathrm{O}_{3}$ with high surface area," Journal of the European Ceramic Society, vol. 23, no. 5, pp. 659-666, 2003.

[14] C. Ma, Y. Chang, W. Ye, L. Duan, and C. Wang, "Hexagon $\gamma$ alumina nanosheets produced with the assistance of supercritical ethanol drying," Journal of Supercritical Fluids, vol. 45, no. 1, pp. 112-120, 2008.

[15] W. Cai, J. Yu, B. Cheng, B.-L. Su, and M. Jaroniec, "Synthesis of boehmite hollow core/shell and hollow microspheres via sodium tartrate-mediated phase transformation and their enhanced adsorption performance in water treatment," Journal of Physical Chemistry C, vol. 113, no. 33, pp. 14739-14746, 2009.

[16] Y.-X. Zhang, Y. Jia, Z. Jin et al., "Self-assembled, monodispersed, flower-like $\gamma$-AlOOH hierarchical superstructures for efficient and fast removal of heavy metal ions from water," CrystEngComm, vol. 14, no. 9, pp. 3005-3007, 2012.

[17] W. Cai, J. Yu, and M. Jaroniec, "Template-free synthesis of hierarchical spindle-like $\gamma-\mathrm{Al}_{2} \mathrm{O}_{3}$ materials and their adsorption affinity towards organic and inorganic pollutants in water," Journal of Materials Chemistry, vol. 20, no. 22, pp. 4587-4594, 2010.

[18] W. Cai, J. Yu, S. Gu, and M. Jaroniec, "Facile hydrothermal synthesis of hierarchical boehmite: sulfate-mediated transformation from nanoflakes to hollow microspheres," Crystal Growth and Design, vol. 10, no. 9, pp. 3977-3982, 2010.

[19] M.-M. Bagheri-Mohagheghi, N. Shahtahmasebi, M. R. Alinejad, A. Youssefi, and M. Shokooh-Saremi, "Fe-doped $\mathrm{SnO}_{2}$ transparent semi-conducting thin films deposited by spray pyrolysis technique: thermoelectric and p-type conductivity properties," Solid State Sciences, vol. 11, no. 1, pp. 233-239, 2009.

[20] S. Banerjee and P. S. Devi, "Effect of citrate to nitrate ratio on the decomposition characteristics and phase formation of alumina," Journal of Thermal Analysis and Calorimetry, vol. 90, no. 3, pp. 699-706, 2007.

[21] H. S. Potdar, K.-W. Jun, J. W. Bae, S.-M. Kim, and Y.-J. Lee, "Synthesis of nano-sized porous $\gamma$-alumina powder via a precipitation/digestion route," Applied Catalysis A, vol. 321, no. 2, pp. 109-116, 2007.

[22] G. Li, J. Smith, H. Inomata, and K. Arai, "Synthesis and thermal decomposition of nitrate-free boehmite nanocrystals by supercritical hydrothermal conditions," Materials Letters, vol. 53, no. 3, pp. 175-179, 2002.

[23] D. Mishra, S. Anand, R. K. Panda, and R. P. Das, "Hydrothermal preparation and characterization of boehmites," Materials Letters, vol. 42, no. 1, pp. 38-45, 2000.

[24] H. J. Kim, T. G. Kim, J. J. Kim, S. S. Park, S. S. Hong, and G. D. Lee, "Influences of precursor and additive on the morphology of nanocrystalline $\alpha$-alumina," Journal of Physics and Chemistry of Solids, vol. 69, no. 5-6, pp. 1521-1524, 2008.

[25] S. Ramanathan, S. K. Roy, R. Bhat, D. D. Upadhyaya, and A. R. Biswas, "Alumina powders from aluminium nitrate-urea and aluminium sulphate-urea reactions: the role of the precursor 
anion and process conditions on characteristics," Ceramics International, vol. 23, no. 1, pp. 45-53, 1997.

[26] X. Zhai, Y. Fu, and G. Chu, "New technology reports combustion synthesis of the nano/structured alumina powder," Nanoscience, vol. 11, no. 4, pp. 286-292, 2006.

[27] K. M. Parida, A. C. Pradhan, J. Das, and N. Sahu, "Synthesis and characterization of nano-sized porous gamma-alumina by control precipitation method," Materials Chemistry and Physics, vol. 113, no. 1, pp. 244-248, 2009.

[28] M. I. F. Macêdo, C. C. Osawa, and C. A. Bertran, "Sol-gel synthesis of transparent alumina gel and pure gamma alumina by urea hydrolysis of aluminum nitrate," Journal of Sol-Gel Science and Technology, vol. 30, no. 3, pp. 135-140, 2004.

[29] M. T. Hernández and M. González, "Synthesis of resins as alphaalumina precursors by the Pechini method using microwave and infrared heating," Journal of the European Ceramic Society, vol. 22, no. 16, pp. 2861-2868, 2002. 

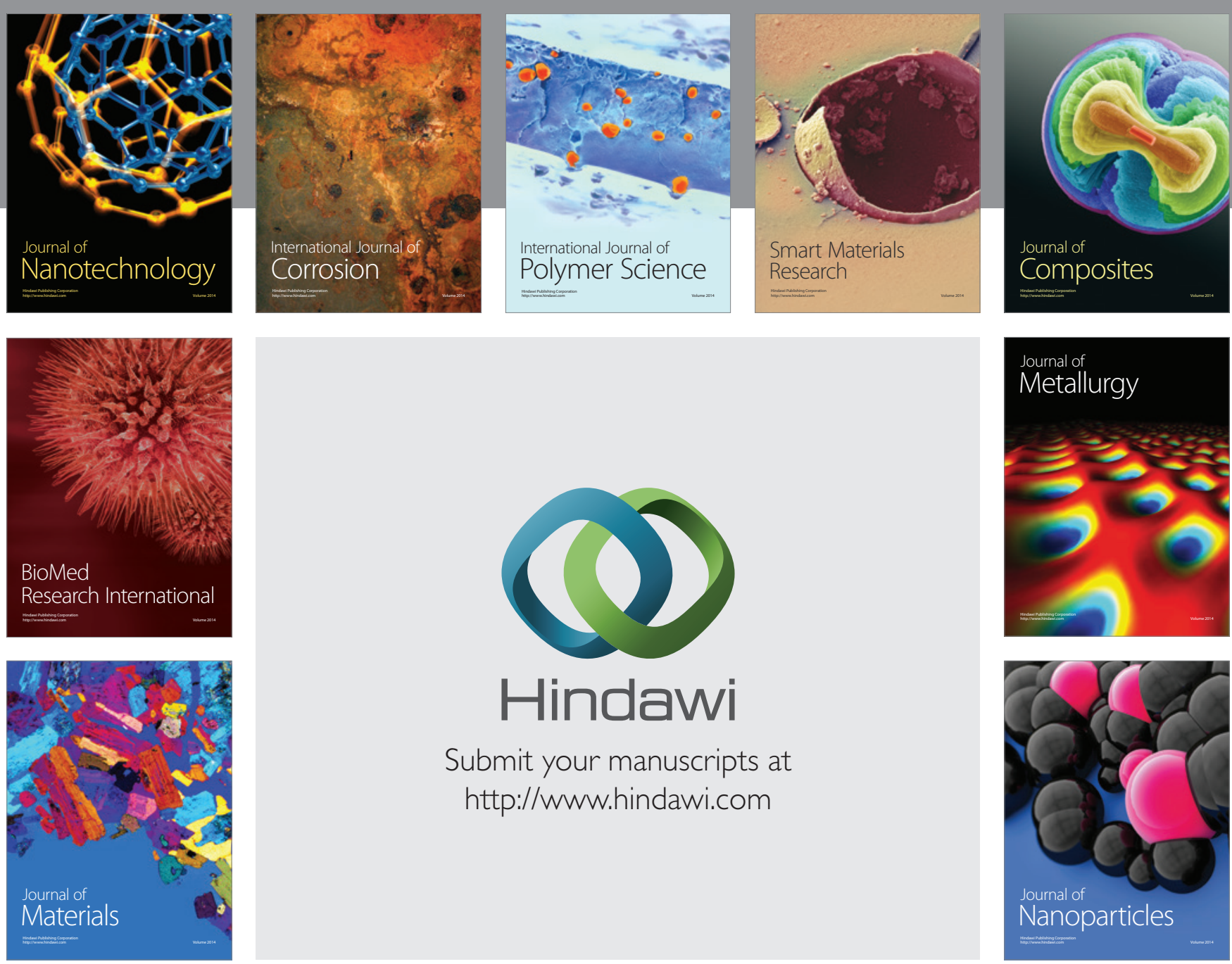

Submit your manuscripts at http://www.hindawi.com
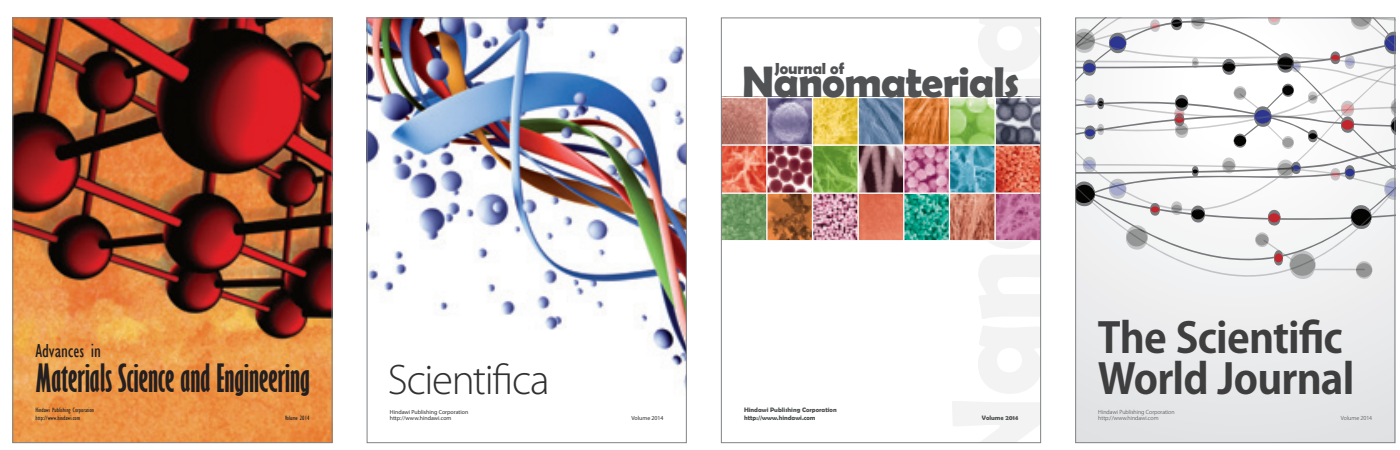

\section{The Scientific World Journal}
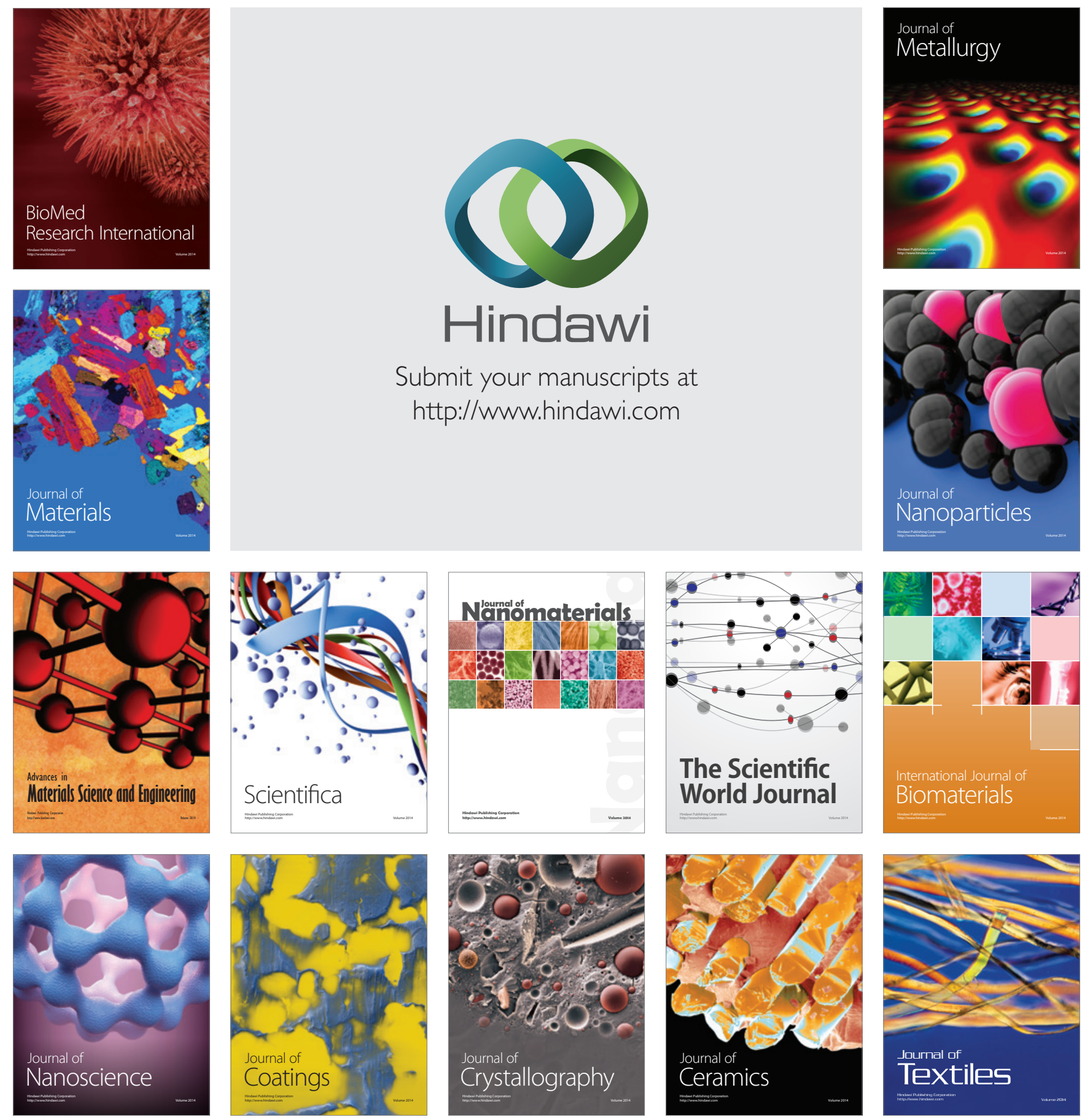